
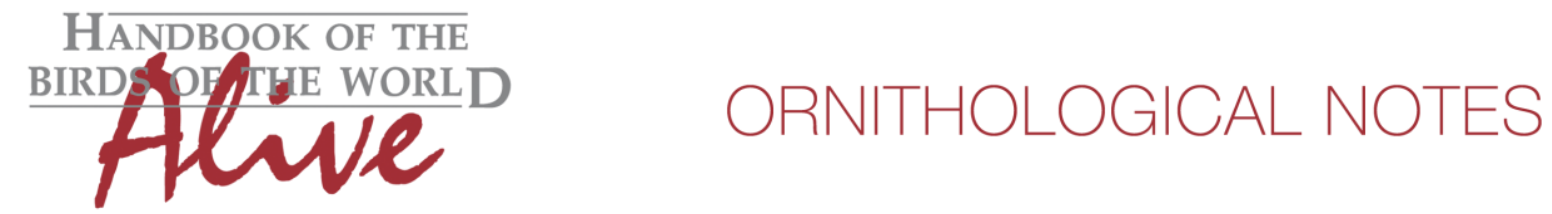

\title{
Notes on the vocalizations of White-streaked Antvireo (Dysithamnus leucostictus)
}

Peter Boesman

In the following we briefly analyze and compare voice of the different races of White-streaked Antvireo. We also try to quantify the extent of any vocal differences using the criteria proposed by Tobias et al. (2010), as a support for taxonomic review.

We have made use of sound recordings available on-line from Xeno Canto (XC) and Macaulay Library (ML).

First of all a note of caution: Song of D.I. tucuyensis has been confused in the past with song of Plain Antvireo D. mentalis. (the description in HBW vol 8. seems erroneous, so is e.g.

ML127811). Reason is probably that both species often occur together in understory flocks, and D.I.tucuyensis is not very vocal. For the same reason, the correct identification of calls is not straightforward. I have therefore limited this analysis to the loudsong of both taxa.

Song of D.I. tucuyensis differs from D.I. leucostictus in having less notes, which are typically longer and flatter in pitch, creating a rather plaintive sound quality. Also, the first note is typically flat in pitch (sometimes even slightly underslurred) and quite different from the subsequent notes, unlike D.I.leucostictus. Notes in the song of D.I. leucostictus are typically more overslurred and shorter, creating more a bouncing melody (Fig. 1).

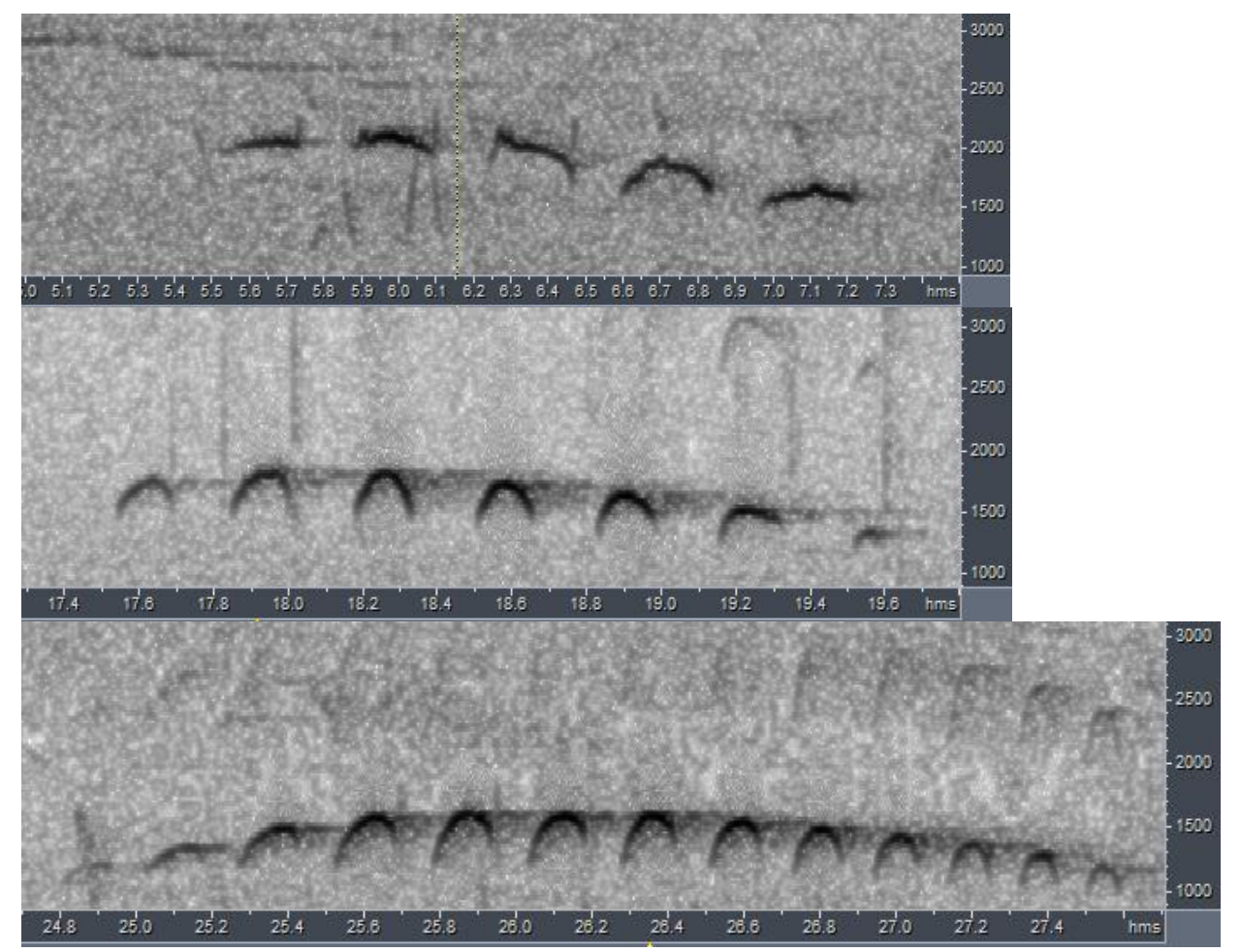

Figure 1: From top to bottom: typical loudsong of D.I.tucuyensis, D.I.leucostictus and D.plumbeus 

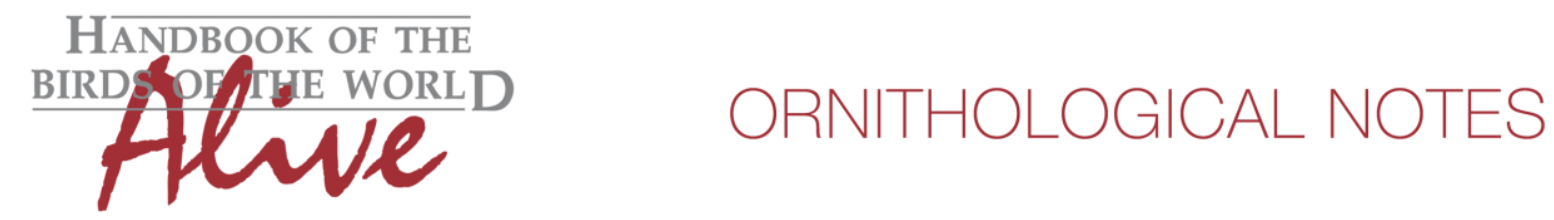

A thorough vocal analysis was made when discussing relationship with Plumbeous Antvireo $D$. plumbeus (Isler et al. 2008). I have used these data to calculate effect size for the different parameters examined, between D.I.leucostictus and D.I. tucuyensis.

There are 5 parameters for which the effect size falls in the range 2-5 (equivalent to a score 2). The highest Effect size is for 'Duration terminal note' (effect size 3.15) and peak frequency (effect size 2.87). This would thus give twice a score of medium, $2+2=4$.

I also calculated the Effect size between D.I.leucostictus and D.plumbeus.

There is 1 parameter with effect size larger than 5 and 5 parameters in the range 2-5.

The highest effect size was for 'Interval length' (effect size 5.46) but this figure would probably drop below 5 if the data of D.I.tucuyensis were merged with D.I.leucostictus (which would seem the logical approach when comparing these two defined species).

The score for $D$. plumbeus is thus at most $3+2$ compared to $D$. leucostictus.

A parameter which was not examined previously, but which seems to be rather significant when looking at sonograms, is the ratio 'note length/interval'.

D.I. tucuyensis has a note length which is always about twice as long as the interval between notes. D.I. leucostictus has a note length which is roughly the same (actually ratio 1.18 ) length as the interval between notes. I have done a quick measurement of the first interval and the second note on 10 songs of each taxon: D.l. tucuyensis $2.76 \pm 0.48$ while D.l. leucostictus $1.18 \pm$ 0.09 resulting in an effect size of 4.6 (score 2 ).

All above measurements indicate that loudsong of the three taxa has roughly the same amount of divergence, with a marginally higher quantified score for D.plumbeus.

For White-streaked Antvireo we can conclude that loudsong of D.I. tucuyensis differs from D.I. leucostictus in having less notes, which are typically longer and flatter in pitch, creating a rather plaintive sound quality. Also, the first note is very flat in pitch (sometimes even slightly underslurred) and quite different from the subsequent notes, unlike D.l.leucostictus, which has all shorter, over-slurred notes, creating a more bouncing melody. Main calculated differences are ratio note length/interval (effect size 4.6, score 2), note length (effect size 3.15, score 2) and peak frequency (effect size 2.87). Total score 4.

This note was finalized on 18th March 2015, using sound recordings available on-line at that moment. We would like to thank in particular the sound recordists who placed their recordings for this species on XC and $\mathrm{ML}$. 


\section{References}

Isler, Morton I., Isler, Phyllis R. and Whitney, B. M. 2008. Species limits in antbirds (Aves: Passeriformes: Thamnophilidae): an evaluation of Plumbeous Antvireo (Dysithamnus plumbeus) based on vocalizations. Zootaxa, 1726: 60-68.

Tobias, J.A., Seddon, N., Spottiswoode, C.N., Pilgrim, J.D., Fishpool, L.D.C. \& Collar, N.J. (2010). Quantitative criteria for species delimitation. Ibis 152(4): 724-746.

Zimmer, K., Isler, M.L. (2003). White-streaked Antvireo (Dysithamnus leucostictus). In: del Hoyo, J., Elliott, A., Christie, D.A. (eds.). Handbook of the Birds of the World Vol. 8. Broadbills to Tapaculos. Lynx Edicions, Barcelona.

\section{Recommended citation}

Boesman, P. (2016). Notes on the vocalizations of White-streaked Antvireo (Dysithamnus leucostictus). HBW Alive Ornithological Note 49. In: Handbook of the Birds of the World Alive. Lynx Edicions, Barcelona. (retrieved from http://www.hbw.com/node/931928 on 29 April 2016). 